\title{
Towards the revival of stone craftsmanship in Egypt: a rediscovery of forgotten literature
}

\author{
A. El-Habashi \& S. Gaafar \\ Monofia University, Egypt
}

\begin{abstract}
Recent practices in the fields of architecture and cultural heritage have proved that stone craftsmanship in Egypt, among many other local crafts, is about to vanish. This paper introduces the magnitude of such deficiency, and highlights the fact that Egyptian natural stones, some of the best available, have shaped distinguishable architectural heritage and identity. The paper revisits various literature that appeared at the turn of the twentieth century where prominent European engineers published studies on the properties and structural performances of Egyptian stones. The then the local government undertook the large-scale construction of barrages, dams and bridges to regulate the floods of the Nile River using local stones. It hired foreign engineers to study the suitability of local materials for such modern structures. The published studies were the bases of designing many of such structures, as well as core references for graduate education in the field of engineering. This paper introduces these studies, which were forgotten once the local manufacturing of steel and cement locally prevailed. Through selected cases derived from such literature, the research demonstrates that those publications can be a catalyst to resume stone craftsmanship on the basis of not only accumulative experiences that started from late antiquities but also on scientific understanding of material properties and building systems. Determining the shapes and the dimensions of various architectural elements, such as stone corbels as one example, would no longer be purely an aesthetic matter, but follows accurate calculations. Consequently the hoped revival would be based on new scientific bases that would give the professionals and craftsmen involved the means to develop the craft from one hand, and to save unnecessary use of materials from the other.

Keywords: Egyptian natural stones, stone craftsmanship, revival.
\end{abstract}




\section{Introduction}

Natural stones were used in Egypt a long time ago and were so influential in the formation of the local architectural heritage due to their special characteristics and properties, and to the accumulative knowledge in quarrying, dressing and using them in construction. At the early phases of the twentieth century, a number of studies were conducted and published to explain how such materials could be used in the construction of modern civil structures primarily aimed to regulate the floods of the Nile River. That was indeed a national objective of the time that quickly drove Egypt to build the first Aswan dam in 1902 and subsequently the high dam in 1960's. In this paper we will revisit those studies, and infer from them important frameworks to be applied in the domain of the construction of buildings with natural stone. The focus is on the calculations of the stone corbels as one example of all building elements that could be constructed out of stones. The hope is to consider the suggested framework for the revival sought for local craftsmanship, and for building construction using natural stones in Egypt.

\section{Natural stones in Egypt}

Egypt and its deserts sit on one of the largest and oldest source of natural stones in the World. Since the dawn of history, Egyptian natural stones, i.e. limestone, sandstone, basalt, granite, alabaster and others, were used in buildings. The remarkable survival of those stones throughout the ages indicates that indeed they are of exceptional quality, and that they exist in a climate that favours its continual existence (Afia [1]). The ancient Egyptian's use of the Nile river to primarily transfer various stone types, of huge masses, to fulfil needs for particular structural circumstances in building pyramids and temples. For those buildings to survive with minimum maintenance and many assaults until the present is an evidence of an exceptional knowledge of the properties of such materials, and of a refined involved craftsmanship. Quarrying, transporting, dressing, and constructing stone blocks are all professions that were mastered producing architecture that is still retaining to this day exceptional values.

Ones of the best sedimentary stones are those found in abundance along the hills bordering the Nile river in Egypt stretching from Cairo to south of Esna for about a distance of 500 miles for limestone and continues south to Aswan and Nubia for sandstone (al-Baqri [2], Harfouch [3]).

\section{The use of natural stone in the $20^{\text {th }}$ century}

The industrial revolution in Europe had its direct implications in Egypt. Cast iron, steel, and later on reinforced concrete were introduced in the local building industry as early as the end of the nineteenth and early twentieth century. The then development boom the country witnessed was too ambitious to wait until those materials to be locally available in order to undertake major public projects. In the early decades of the twentieth century, the Egyptian government 
set a strategic objective to regulate the flooding of the Nile to allow development to take place along the river's banks. Building canals, dams and barrages, along with railways and bridges was the Government's priority that necessitated considering the use of the local natural building materials in the first place since the newly introduced ones were still scarce and unavailable in the needed quantities. The local government appointed prominent European engineers, mostly British, not only for the design of the required structure following the highest specifications, but also to do so using materials that were locally available. In parallel, it also established local educational system that would have such engineers forming local Egyptian cadres to deal with the traditional building materials in a scientific basis to sustain the then required construction campaigns. Those engineers transferred scientific knowledge of the properties of materials, and taught how to calculate loads and stresses on various different structural elements. This knowledge differed radically from the local system of construction, which was based on the local craft enterprises, learning through experiments and accumulated experiences.

The aim was to develop the conventional construction techniques by acquiring skills not only throughout diligence and practices, but also through the considerations of modern scientific studies, techniques and mechanization. This would not only ensure the safety and stability of the structures, but also the use of the material to the necessary extent without waste. The foreign engineers and scientists brought to the country began by studying the scientific properties of the local building materials, among which the natural stones, and to propose techniques to be followed in the construction based on the then available sciences and machineries. As a result, a wide range of distinct and important scientific books were locally published to educate the public and to be used as primary references in the newly set educational system. Considered as pure engineering matters, this important scientific material was limited in their applications to the domain of Civil Engineering in order to quickly materializing the objectives of the local government, and was never communicated to local architects and craftsmen. To mention few of these important books published on the subject are those of Hume et al. [4], Lucas and Harris [5], and Rice-Oxley [6].

Such literature, among many other important studies, offered in depth analysis of the properties of local stones through accurate experimentations, and presented calculations for the selection of various kinds of stones to be employed in construction. It also illustrated various modern techniques and machineries that can be specified to achieve the tasks. It should have been widely used to develop local related crafts, but this was not the case because of limiting its use on certain industrial and public facilities merely in need at the time.

Printed by the Egyptian Government, most of these books have appeared in the first decade of the twentieth century. Such wealth of literature was not picked up by the following local generations, with only a few exceptions e.g. al-Leithy [7], Omar and Saleh [8], Salih [9] and Thabet [10]. In fact, it totally disappeared from the current local education curriculum even in the civil engineering fields 
themselves, which are currently focused on studying reinforced concrete, steel and other currently developing building materials.

\section{Towards the revival of Egyptian stone craftsmanship}

In this paper, we are presenting means on how to re-utilize the mentioned literature to infer frameworks to design architectural elements out of locally available stones. Here, the 1916s book of Rice-Oxley [6] is examined as an example on how to reinterpret presented scientific arguments for the benefit of architects and craftsmen. The book refers to the traditional arts of building with stones developed in ancient Egyptian civilization, and explains that until relatively recent such traditional modes of construction were the available reference to learn how to employ stones in buildings especially that the ancient structures in reference remained stable and balanced for ages. Rice-Oxley indicated that the experience has shown that this equilibrium and stability was often the result of non-economic and exaggerated use of the material, and urged for evaluating these ancient experiences through available sciences and knowledge in order to accentuate the use of materials, and to make it more efficient and correct. It is this very notion that made the re-discovery of this book, and many similar ones, crucial in order to offer better understanding of the traditional architecture, to pave the way to developing it in modern schemes and uses, to propose a more environmental friendly building industry, and to incite a new mode of local architecture that is more compatible with local urban heritage.

In the case of the use of steel and reinforced concrete in buildings we ought to base the designs on exact calculations, standard dimensions, and limits of allowable stresses, putting in consideration safety coefficients to mainly overcome defects in the manufacturing of such materials. Therefore, the knowledge of the exerted forces and weights was translated into sets of segments and dimensions of such materials accurately and economically calculated. In the case of using stones in construction, the matter is different. Being a natural substance, its composition is often quite irregular; therefore the safety factors in calculating dimensions of its units are high to overcome such deficiency. However, it is with the ongoing theoretical and practical studies of these materials and their properties that more accurate results can be achieved. Lessening the coefficient of safety in determining the required dimensions shall then be on the basis of avoiding errors and using the material more efficiently.

\section{Examples on evaluating traditional stone corbels}

Among the cases analysed in his book, Rice-Oxley studied the stress on a plane section to non-axial or eccentric loads such as in the reservoir of a dam whose section is shown in Fig 1. Assuming the reservoir to be empty and considering unit length of the dam, the only force acting on the base XY is the weight $\mathrm{W}$ of unit length of dam acting through the centre of gravity of the section. The line of action of $\mathrm{W}$ cuts the base $\mathrm{XY}$ at the centre of pressure, of which obviously is nearer to $\mathrm{X}$ than to $\mathrm{Y}$ and, therefore, the distribution of pressure on the plane 
section $\mathrm{XY}$ is not uniform, but the stress of pressure per unit area will be greater at $\mathrm{X}$ than at $\mathrm{Y}$. The force on the plane section $\mathrm{XY}$ is a non-axial one, and the distribution of stress has to be determined [6, pp. 72-73].

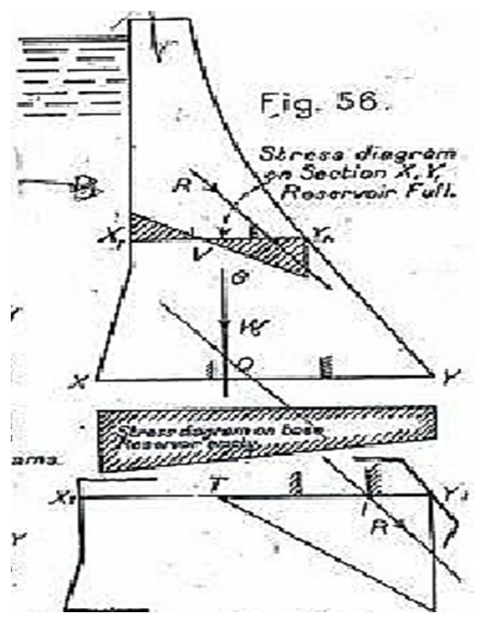

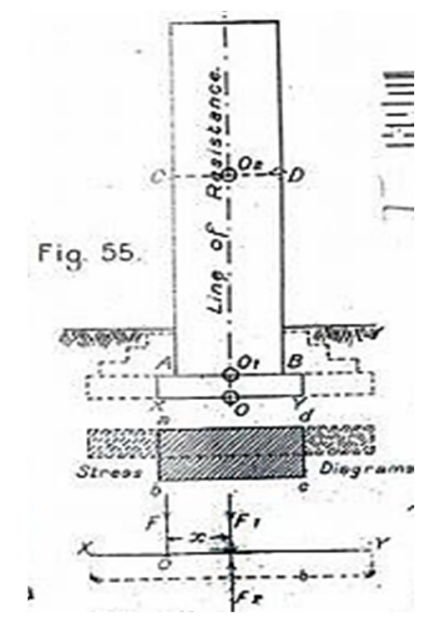

Figure 1: (a) retaining wall; (b) forces [6].

If $\mathrm{XY}$ in Fig. 1(a) is considered to be the trace of a horizontal rectangular section of unit length, and $\mathrm{F}$ in Fig. 1(b) to be the resultant vertical force acting on the section at the point $\mathrm{O}$, the distance of $\mathrm{O}$ from the centre of the section being $\mathrm{x}$. This distance is known as the "eccentricity" of the resultant force on the section. It is required to determine the distribution of vertical stress on the plane section XY. If two equal and opposite forces F1 and F2 are assumed, each equal to $F$, to be applied at the centre of the section; then these two forces being equal and opposite will have no effect on the resultant stress on the section and are assumed for purposes of calculation only. On such bases, F1 acting at the centre of the section causes a uniform stress that equals to $\frac{\mathrm{Ft}}{\text { area of section }}$.

The two remaining forces F and F2 form a couple whose moment is Fx. The case is analogous, as far as this couple is concerned, to a loaded beam of rectangular section of depth $\mathrm{b}$ and unit width, the neutral axis being at a distance of $b / 2$. If $p$ be the stress at the extreme fibres of the beam, it can be proved that $\frac{\mathrm{M}}{\mathrm{I}}=\frac{\mathrm{p}}{ \pm \mathrm{b} / 2}$, where $\mathrm{M}$ is the external bending moment on the beam, and $\mathrm{I}$ the moment of inertia of the section under consideration. Normally, $p$, which is the external bending moment, equals to Fx. Therefore:

$$
\mathrm{p}=\frac{\text { F.x.b }}{2 \mathrm{I}}, \quad \text { or } \quad \frac{2 \mathrm{p}}{ \pm \mathrm{b}}=\frac{\mathrm{F} \cdot \mathrm{x}}{\mathrm{I}}
$$

$\mathrm{P}$ being the stress at the outer edges, i.e. at $\mathrm{X}$ and $\mathrm{Y}$, due to the forces $\mathrm{F}$ and $\mathrm{F} 2$ but in addition the force $\mathrm{F} 1$ causes a positive stress $\mathrm{F} / \mathrm{b}$ at $\mathrm{X}$ and $\mathrm{Y}$ (calling compressive stresses positive and tensile stresses negative). Therefore, the total 
stresses due to the forces F, F1, and F2 at $Y=\frac{F}{b}-\frac{F \cdot x \cdot b}{2 I}$, and at $X=\frac{F}{b}+\frac{F \cdot x \cdot b}{2 I}$. Since F1 and F2 are equal and opposite, they cancel one another and have, therefore, no effect on the stress. The stress, $\mathrm{p}$ max or min, due to $\mathrm{F}$ at $\mathrm{X}$ and $\mathrm{Y}$, is given by $\mathrm{P} \max$ or $\min =\frac{\mathrm{F}}{\mathrm{b}} \pm \frac{\text { F.x.b }}{2 \mathrm{I}}$ but $\mathrm{I}=\mathrm{b} 3 / 12$ for a rectangular section of depth $\mathrm{b}$ and unit width. As a result the following equation is considered:

$$
\text { Pmax or } \min =\frac{\mathrm{F}}{\mathrm{b}} \pm \frac{6 \cdot \mathrm{F} \cdot \mathrm{x}}{b^{2}}
$$

Rice-Oxley calculations can also be used in determining the stresses which are exerted on architectural elements projecting horizontally from a vertical wall, such as stone corbels. Retaining walls calculated by Rice-Oxley, however, are affected by two encountered forces, which are the wall's weight, and the bending moment. The first tends to neutralize the second. In the case of the cantilever the matter is different, since the effective bending moment results from both the loads exerted on the cantilever and the cantilever's own weight. The Rice-Oxley equation, therefore, shall be slightly modified by having $\frac{\mathrm{F}}{\mathrm{b}}=0$. In the case of corbels, eq. (2) can be modified as follows:

$$
\text { Pmax or } \min =\frac{6 . F \cdot X}{b^{2}}
$$

\section{Stone corbels: case studies}

Stone corbels are common structural elements used to carry projections above. They consist of several combined pieces of stone, segments of which are shown outside of the building and the remaining are inside bearing walls. They cantilever so as to transfer the eccentric loads and distributed them back on the bearing wall underneath. A large variety of forms and shapes of those corbels were traditionally used; each reflects both the loads carried, and a certain
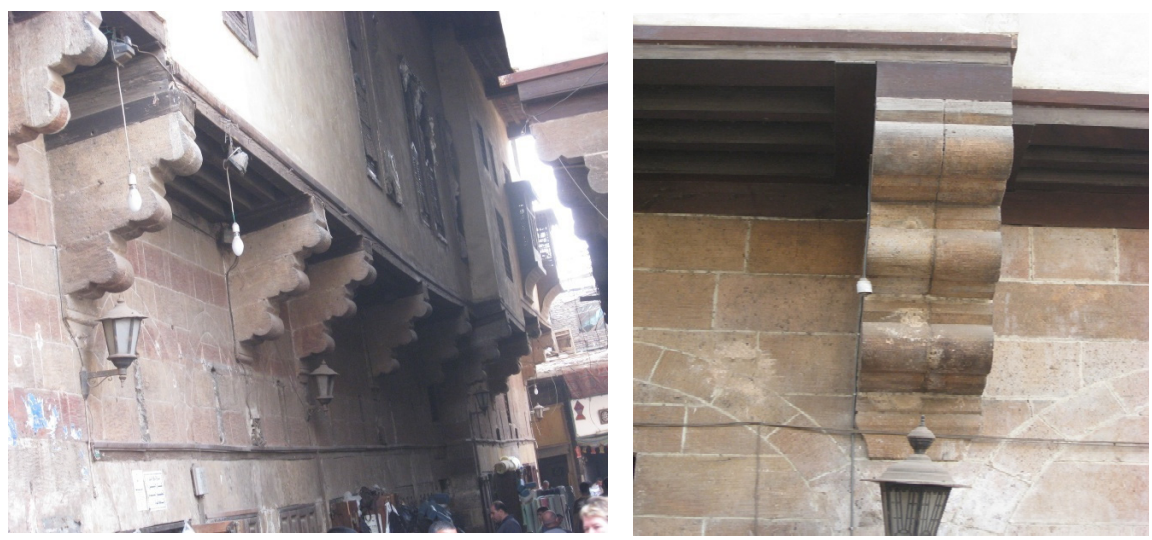

Figure 2: (a) corbels; (b) detail. 
aesthetic consideration that reflects the status of the buildings where they were used. Although being a construction element, their form and aesthetic values stand out as shown in the photographs. For the purpose of this paper, we have selected two different cases to analyse. The first is of a corbel that carries the floor projection and a parapet built at its critical tip, and the second carried not only a projection but a high solid wall pierced with large window openings.

\subsection{Case study 1}

The first example concerns a sixteenth century building in historic Cairo. In its courtyard, a series of stone corbels carry a projecting floor as well as to a masonry parapet at its tip. Each corbel is composed of 4 stone pieces (2 lower and 2 upper), each with a section of $20 \mathrm{~cm}\left(\mathrm{~b}_{\mathrm{c}}\right)$ by $30 \mathrm{~cm}\left(\mathrm{t}_{\mathrm{c}}\right)$. It is projected 140 $\mathrm{cm}$ of which only $60 \mathrm{~cm}$ are of stone as shown in sketch of Fig. 4 . These stone corbels failed, cracked and were complemented in a later phase with additional wooden supports as shown in the photographs. The restorer of the site wanted to restore the original structural system and remove the imposing wooden supports. The corbel is carrying its own load (D.L), and subjected to others (L.L). In such case we can calculate the exerting forces as follows:
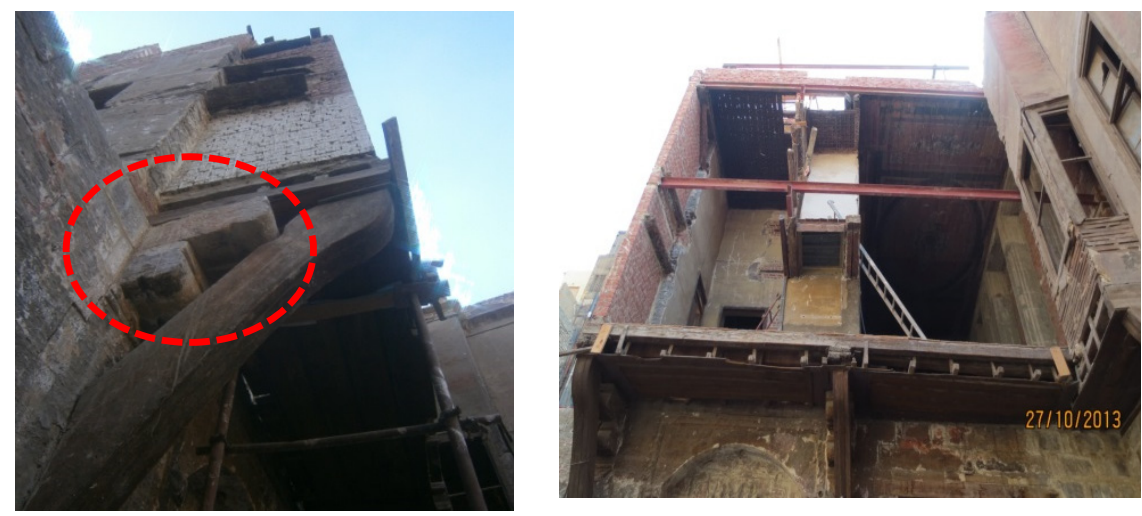

Figure 3: Corbels of example 1.

The total load $\left(\mathrm{W}_{\mathrm{f}}\right)$ equals the addition of the own weigh (O.W) and live load (L.L) given the assumption that it includes a height of 1 meter stone parapet. The calculation of the slab weight (O.W.) in a section of square meter of the wooden floor is calculated to be $0.11 \mathrm{t} / \mathrm{m}^{2}$, and the live load (L.L) to be $0.2 \mathrm{t} / \mathrm{m} 2$, which makes the total load $\left(\mathrm{W}_{\mathrm{F}}\right)$ to be $0.31 \mathrm{t} / \mathrm{m}^{2}$. The total load on the stone corbel would then equals to the own weigh of corbel $\left(\mathrm{O} . \mathrm{W}_{\text {stone }}\right)$ in addition to the $\mathrm{W}_{\mathrm{f}}$.

$$
\mathrm{W}_{\mathrm{c}}=\delta_{\mathrm{s}} \times \mathrm{t}_{\mathrm{s}} \times \mathrm{b}_{\mathrm{s}} \times \mathrm{l}_{\mathrm{s}} \times \mathrm{n}+\frac{\text { Area of the floor } \times \text { load on the floor }}{\text { corbel length }}
$$

The above equation is based on $\left(\delta_{\mathrm{s}}\right)$ to be the stone density, $\left(\mathrm{t}_{\mathrm{s}}\right)$ as the height of the corbel, $\left(b_{s}\right),\left(l_{s}\right)$ the length of the projection, and $(n)$ is the number of 
stones making the corbel, four in this case. The calculated maximum floor area carried by the stone corbel is $5.88 \mathrm{~m}^{2}$, making the load on the stone corbel $\left(\mathrm{W}_{\mathrm{c}}\right)$ following eq. (4) to be $2.7 \times .3 \times .2 \times .6 \times 4+\left[\frac{5.88 \times .31}{.6}\right]=3.43 \mathrm{t} / \mathrm{m}$, which is $\mathrm{F}$ in Rice-Oxley equation.

Using eq. (3) derived from Rice-Oxley, the following can be concluded:

$$
\mathrm{P}_{\max }=\frac{6 \times 3.43 \times 0.6}{0.2^{2}}=308.7 \mathrm{t} / \mathrm{m}^{2}
$$

Rice-Oxley analyses of local stones indicate that the maximum allowable tensile strength that it can sustain is $880 \mathrm{t} / \mathrm{m}^{2}$ [6, p. 198]. The maximum range of tensile per square meter is used here so that we can identify the maximum load a stone cantilever can carry. However, in the design process we should use the minimum range of that tensile in order to assure the stability of the structure even if the stone used is of low quality. $\mathrm{P}$ actual $<\mathrm{P}$ allowable $=$ Safe design.
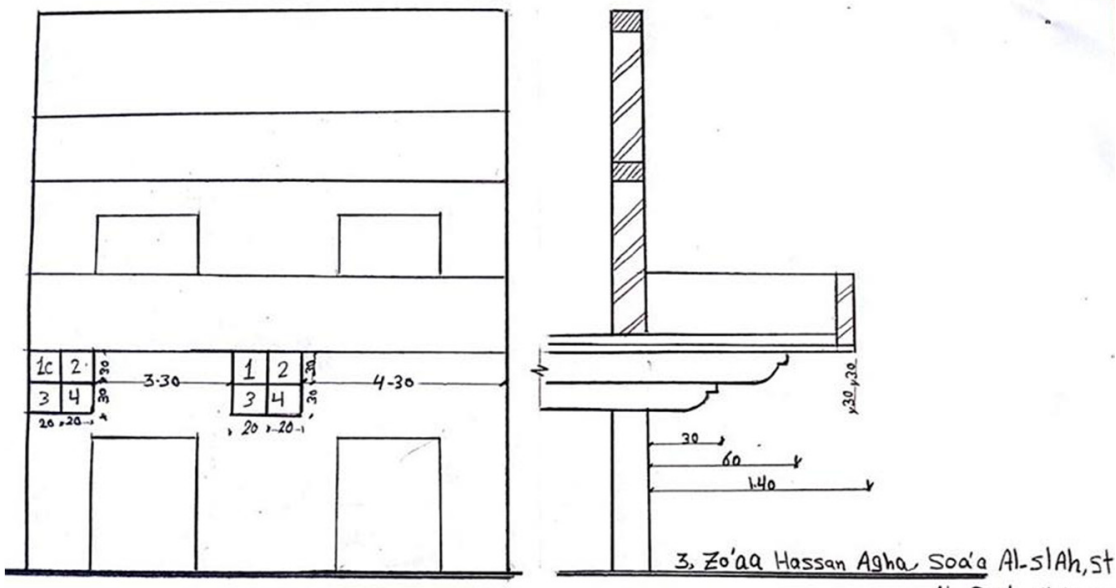

Al-Darb Al Ahma

Figure 4: Sketch of example 1.

We notice that the actual stresses subjected to the stone $308.7 \mathrm{t} / \mathrm{m}^{2}$ is much less than the allowable stresses (880), which means that the stone corbel is under used by almost its third carrying capacity. Such calculation confirms that stresses at corbels of the first examples are much less than the minimum allowable stresses, and the stone corbel is safe to use. But it also means that it can carry much more than it actually does. The designer/craftsmanship could have used much less of stone section, or either widens the spacing between the corbels to enlarge the amount of loading exerted of the corbels.

If we are to design these stone corbels projecting the $0.6 \mathrm{~m}$ using $230 \mathrm{t} / \mathrm{m}^{2}$ as the minimum reported stress similar sandstones would sustain $\left(\mathrm{P}_{\min }\right)$ [6, p. 198], the calculations would be as follows:

$$
\mathrm{P}_{\min }=230=\frac{6 \times 3.43 \times 0.6}{b^{2}}
$$




$$
\mathrm{b}=\sqrt{\frac{6 \times 3.43 \times \cdot 6}{230}}=\sqrt{0.0537}=0.23 \mathrm{~m} .
$$

This means that the actual $0.2 \mathrm{~m}$ of the stone corbel will not provide a safe design to sustain all stresses in the case if the stone used is of the lowest category. In this case, there is a must to select a good quality stone.

\subsection{Case study 2}

The second example concerns the exterior of an early twentieth century house in historic Cairo. It is designed by an Italian architect by the name of Achille Patricolo. Here, there are three stone corbels carrying a projecting mass with a several windows opening pierced to reduce the dead loads. Each corbel is composed of 3 pieces of stone one on top of the other. Each stone piece is of a section of $40 \mathrm{~cm}\left(\mathrm{~b}_{\mathrm{c}}\right)$ by $90 \mathrm{~cm}\left(\mathrm{t}_{\mathrm{c}}\right)$, and projected $60 \mathrm{~cm}$. Each is carrying its own load (D.L), and subjected to others (L.L). Similar to the same flow of calculations followed in the first examples, but applying the parameters of the second case we have the following:

Load on corbel $\left(\mathrm{W}_{\mathrm{c}}\right)=$ own weigh of corbel $\left(\mathrm{O} . \mathrm{W}_{\text {stone }}\right)+$ load from the floor $\left(\mathrm{W}_{\mathrm{f}}\right)+$ load of wall built on the tip of the corbel $\left(\mathrm{P}_{\mathrm{w}}\right)$
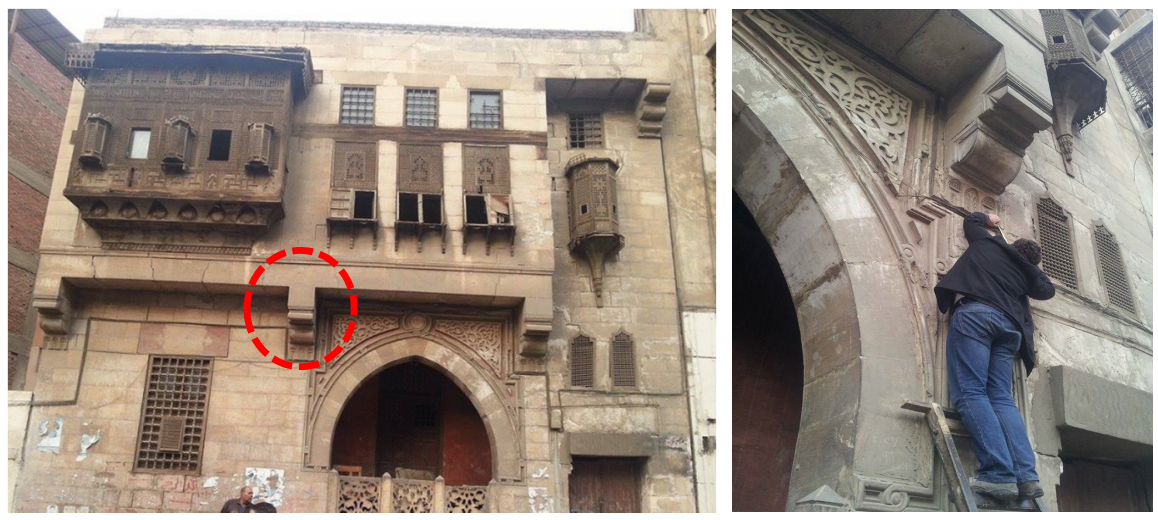

Figure 5: Façade of example 2.

The calculation of the slab weight in a section of square meter of the wooden floor is calculated to be $0.11 \mathrm{t} / \mathrm{m}^{2}$, and the live load (L.L) to be $0.2 \mathrm{t} / \mathrm{m}^{2}$, which makes the total load $\left(\mathrm{W}_{\mathrm{f}}\right)$ to be $0.31 \mathrm{t} / \mathrm{m}^{2}$. The total load on the stone corbel would then equals to the own weigh of corbel $\left(\mathrm{O} . \mathrm{W}_{\text {stone }}\right)$ in addition to the $\mathrm{W}_{\mathrm{f}}$ as well as the weight of the stone wall built on the exterior extremity of the corbel $\left(\mathrm{P}_{\mathrm{w}}\right)$. We should note that in this case the result were not multiplied by 4 as we don't have the scenario of having four stones projecting as in the first example.

$$
\mathrm{W}_{\mathrm{c}}=\left[\delta_{\mathrm{s}} \times \mathrm{t}_{\mathrm{s}} \times \mathrm{b}_{\mathrm{s}} \times \mathrm{l}_{\mathrm{s}} \times \mathrm{n}\right]+\left[\frac{\text { floor area } \times \text { load on floor }}{\text { corbel length }}\right]+\left[\delta_{\mathrm{w}} \times \mathrm{t}_{\mathrm{w}} \times \mathrm{b}_{\mathrm{w}} \times 1_{\mathrm{w}}\right]
$$


Considering that the Floor Area carried by the stone corbel $=(1.65+.4+.2+$ $2.17) \times .6=2.75 \mathrm{~m}^{2}$, and the load of the exterior wall $\left[\delta_{\mathrm{w}} \times \mathrm{t}_{\mathrm{w}} \times \mathrm{b}_{\mathrm{w}} \times 1_{\mathrm{w}}\right]$ was calculated on the middle corbel of the façade, thus the most critical without taking into consideration the large openings pierced, in order to exert the maximum loads on the corbels, the following calculation is then applied: $\mathrm{W}_{\mathrm{c}}=$ $[2.7 \times 0.9 \times 0.4 \times 0.6 \times 1]+\left[\frac{2.75 \times 0.11}{0.6}\right]+[2.7 \times 0.25 \times 4.5 \times 5]=16.27 \mathrm{t}$.

Using eq. (3) derived from Rice-Oxley, the following can be concluded:

$$
\mathrm{P}_{\max }=\frac{6 \times 16.27 \times 0.6}{0.4^{2}}=366.08 \mathrm{t} / \mathrm{m}^{2}
$$

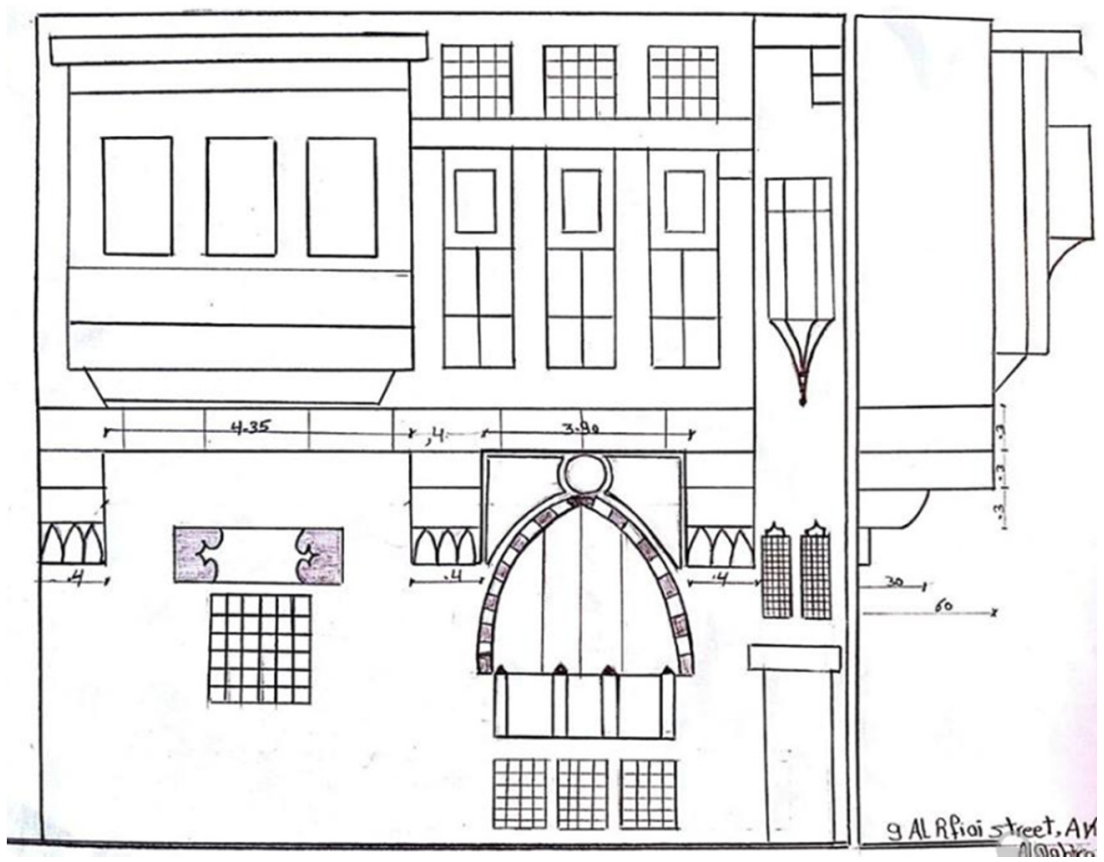

Figure 6: $\quad$ Sketch of example 2.

Considering the maximum allowable tensile strength that a good quality stone can sustain is $880 \mathrm{t} / \mathrm{m}^{2}$ [6, p. 198], we conclude that since the actual stresses subjected to the stone approximately $366 \mathrm{t} / \mathrm{m}^{2}$, the stone corbel is still under used by almost more than half of its carrying capacity. The calculations confirmed that in the second case, the stone is under more stresses than in the first case, but its large section, and possibly its quality that seems to be much better, allowed the corbels to survive in good condition. The designer/craftsmanship of this case could have used less of stone used, or either widens the spacing between the corbels to enlarge the amount of loading exerted of the corbels. It seems, however, the considerations here were based more on aesthetic qualities, and that 
the Italian designer was mimicking traditional proportions in his revival of local architectural modes.

If we are to design these stone corbels projecting the $0.6 \mathrm{~m}$ using $230 \mathrm{t} / \mathrm{m}^{2}$ as the minimum reported stress similar sandstones would sustain $\left(P_{\min }\right)$ [6, p. 198], the calculations would be as follows:

$$
\begin{gathered}
\mathrm{P}_{\min }=230=\frac{6 \times 16.27 \times 0.6}{b^{2}} \\
\mathrm{~b}=\sqrt{\frac{6 \times 16.27 \times 0.6}{230}}=\sqrt{0.25466}=0.50 \mathrm{~m} .
\end{gathered}
$$

This means that the actual $0.4 \mathrm{~m}$ of the stone corbel will certainly fail to sustain all stresses in the case if the stone used is of the lowest category. In this case, as in the first, there is a must to select a good quality stone.

\section{Conclusion and recommendations}

This paper confirms that the accumulative experiences in constructing with natural stones are quite rich, but they were all based on failures and successes. Aesthetic values of the final product, however, were highly evaluated that efficiency and stability often came as secondary criteria. The irregularity of the natural substance impedes the possibility to have modern engineers and architects relying on the material. It is for that reason that engineers tends to rely more on man-made building materials whose properties can be guaranteed. It is only the scarcity of such modern building materials in Egypt at the turn of the twentieth century that made the Egyptian Government focusing on studying local stones, already known since the antiquities of their supreme qualities. The produced studies, which were quickly forgotten and never used in architectural domains, are considered here an opportunity to re-introduce the material in the construction industry, but in more scientific manner; thus more economical use of the material to produce efficient structural stability.

Through two examples of stone buildings, the traditional stone corbels are structurally evaluated to determine the minimum and maximum dimensions of the required stone elements. These exercises, whose essence are borrowed from historic studies and calculations, with slight modifications, appear to be an incentive to revive the local crafts related to stone construction. The revival will not only be based on accumulated experiences craftsmen acquired throughout ages, but also on the basis of scientific understanding of the properties of these materials and construction systems. This will reduce not only the error rates, but more importantly the use of the unnecessary excess of materials. We think that this will lead to incite local architects to reconsider local building materials to be employed efficiently to provide calculated safety and stability required by modern construction codes.

This paper sets some important recommendations:

1. Stone corbels, among all other building elements, should not be designed based on forms and aesthetic values, but also on precise calculations and safety to prevent overloading and failures; 
2. Stones to be used in structural elements should be accurately analysed to use its actual physical properties in designing such elements;

3. The revival of traditional craftsmanship, especially those related to building construction, should encounter beside heritage values, structural, environmental, economic as well as social parameters;

4. It is important to learn from the ancient as well as the recent past experiences and knowledge in developing local craftsmanship. Such wealth of knowledge, experiences, and literature are indispensable sources to develop a better understanding of the traditional architecture and the development of local construction modes. The use of modern building materials is certainly encouraged, but should not be on the price of the traditional building materials and craftsmanship. The later should always be the source to develop the earlier in order to sensibly respect local environmental and heritage parameters;

5. It is important to develop means of studying building materials and conventional construction methods, and not to rely on simply acquiring skill through practices and diligences. The inclusion of modern scientific studies, techniques and mechanization would ensure the safety of buildings and their elements on one hand, and, from the other side, would economize the use of the materials to perform their functions without waste.

\section{References}

[1] Afia, Mohammed Sameea. Adwaa' ala astkhrag wa astkhdam el maaden wi el sikhoor abr el-hadarat Al-Masrya (lights on the extraction and the use of metals and rocks throughout civilizations, Cairo: General Authority for Geological Survey and Mining Projects, 1996, p. 6.

[2] al-Baqri, Abdil-Latif Abu al-Ata. Al mausua el-handasai li-insha' elmabani wa el-marafiq al 'amaa (Engineering encyclopedia for building construction and public works) Volume I, Cairo: al-shuruq, 2003, p. 303.

[3] Harfouch, Adel Saad Ahmed. Taqyim khamat wa taqaniyat Al-bina' Altaqledya bi-al-mabani al-asriyya bi masr (evaluation of traditional building materials and technologies in contemporary buildings in Egypt), Cairo University, 2009, p. 60.

[4] Hume, W.F. et al. The Building Stones of Cairo Neighbourhood and Upper Egypt, Cairo: Egyptian National Printing Department, 1910.

[5] Lucas, A. and Harris, J.R. Ancient Egyptian Materials and Industries, N.Y.: Dover, 1999.

[6] Rice-Oxley, M.K. Masonry Engineering Structures, Cairo Government Press, Egyptian Ministry of Education, 1916.

[7] al-Leithy, Hussein. ahgar al-bina' wa al-zina fi masr (construction and decorative stones in Egypt), 2003, p. 7.

[8] Omar, Ahmed Hosny and Saleh, Mohammed Hussein. Fi insha' almabany (on constructing buildings), second volume, Cairo: al-'Itimad Press, 1928. 
[9] Salih, Mohammed Hussayn. Handasat al-mabani wa al-insha'at (The engineering of buildings and structures), volume 1; mawad al-bina' (building materials), volume 2, Cairo: dar al-kutub al-mazriyya, 1930.

[10] Thabet, Nadia Mohammed. Dur al-taqaniyat al haditha fi tahqiq estdamt masader wi mawad al bnaa al tabi'iyya: aal-akhshab wa al-ahgar (The role of new technologies in achieving sustainable sources of natural building materials-wood and stone),Moatmar al azhar Al handasi al-dawli Al- tamen, Azhar eighth international conference, 2004. 